\title{
The vaping crises in the United States: a regulatory failure? Lukasz Gruszczynski ${ }^{*} \&$ Margherita Melillo ${ }^{* *}$
}

\section{Introduction}

The popularity of electronic cigarettes (e-cigarettes) has been steadily rising over the last decade. It is estimated that today around 41 million people vape worldwide. ${ }^{1}$ Despite this striking increase in usage, for a long time e-cigarettes attracted only limited attention of the general public. Recently things have changed, however, with e-cigarettes regularly occupying the headlines of major newspapers around the world. This new 'popularity' of e-cigarettes is connected with the outbreak of a vaping-related illness (the so-called 'E-cigarette or Vaping Product Use-Associated Lung Injury' or EVALI ${ }^{2}$ ) in the United States (US), which already has led to 55 deaths and more than 2,500 hospitalized patients. ${ }^{3}$ The EVALI outbreak has also coincided in time with alarming news about the growing popularity of e-cigarettes among American teenagers. ${ }^{4}$ These two vaping crises demand that we reflect on the strengths and weaknesses of e-cigarette regulatory regimes in order to understand how to prevent the repetition of similar events in the future.

Accordingly, this report proceeds as follows: The first part provides a brief introduction to the vaping phenomenon and to the regulatory challenges it poses. The second part looks at the regulatory regime of the US through the lens of the two vaping-related crises that unfolded there between 2018 and 2019. In the third section, the report examines the regulatory regime for e-cigarettes applicable in the European Union (EU), and analyses whether it is effective in preventing similar vaping crises. In this respect, we argue that while a more prompt and stricter regulatory system could probably have mitigated the current vaping crises in the US, the EU legal framework for e-cigarettes could not prevent an EVALI-type epidemic. The fourth section attempts to assess the impact of the two crises on the future of nicotine-based vaping products, while the last part offers some general conclusions.

\section{Regulating e-cigarettes}

\footnotetext{
* Associate Professor, Kozminski University (Poland); Research Fellow, CSS Institute for Legal Studies (Hungary).

** Ph.D. Candidate, European University Institute (Italy); Research Fellow, Max Planck Institute Luxembourg for Procedural Law (Luxembourg).

${ }^{1}$ L. Jones, How Many People Vape?, BBC News, 15 September 2019, <https://www.bbc.com/news/business44295336> accessed 10 January 2020.

${ }^{2}$ D.A. Siegel et al. Update: Interim Guidance for Health Care Providers Evaluating and Caring for Patients with Suspected E-cigarette, or Vaping, Product Use Associated Lung Injury - United States, October 2019, 68 The Morbidity and Mortality Weekly Report 919 (2019).

${ }^{3}$ Centers for Disease Control and Prevention, Outbreak of Lung Injury Associated with the Use of E-Cigarette, or Vaping, Products, updated 31 December 2019, <https://bit.ly/2SA6wR8> accessed 10 January 2020.

${ }^{4}$ Assistant Secretary for Health (ASH), Surgeon General Releases Advisory on E-Cigarette Epidemic among Youth, HHS.gov, 17 December 2018, <https://www.hhs.gov/about/news/2018/12/18/surgeon-general-releasesadvisory-e-cigarette-epidemic-among-youth.html> accessed 10 January 2020.
} 
E-cigarettes are battery-powered devices that are designed to heat up a special liquid, releasing in this process an aerosol that is inhaled by a user. E-cigarettes were invented in 2003 in China, but they began to be marketed on a broader scale only in 2006-2009. They come in a great variety of different models. Initially they visually resembled combustible cigarettes, but more recent products have lost this feature and may look, for example, like pens or USB flash drives. $^{5}$

The scientific community remains deeply divided over the safety of e-cigarettes. Some experts highlight their risk reduction potential as compared to traditional tobacco products (i.e. due to the lack of a combustion process), ${ }^{6}$ while others stress that our knowledge about the long-term effects of their use is limited. ${ }^{7}$ There are also those who express more systemic concerns. For example, some public health experts fear that e-cigarettes may lure a new generation of non-smokers into nicotine addiction, with many users switching later to conventional tobacco or permanently staying with vapour products. ${ }^{8}$ E-cigarettes may also potentially lead to the social renormalization of smoking and re-legitimatize the tobacco industry. Science so far has not been able to provide any decisive answers to many vital questions. While on the basis of the available scientific evidence it appears that the use of ecigarettes may be a preferable option for current smokers who are unwilling or unable to quit, the more general consequences of their presence on the market either remain unclear or are troubling (e.g. the prevalence of e-cigarette usage among teenagers in some countries).

Absent scientific consensus, different States have decided to take starkly different regulatory approaches to e-cigarettes. There are those which prohibit their sale and/or possession altogether (e.g. Argentina, Singapore, and Australia) or restrict access to them by classifying e-cigarettes as medicinal/pharmaceutical products (e.g. Japan and Chile). Others take a more liberal approach, subjecting e-cigarettes to the existing tobacco control rules (e.g. South Korea and Azerbaijan) or designing sui generis regimes (e.g. the EU, New Zealand and the US). Finally, many countries do not have any special rules for e-cigarettes and simply subject them to the general consumer protection standards. This regulatory heterogeneity is also reflected at the international level. So far, the Conference of the Parties of the Framework Convention on Tobacco Control has failed to provide any precise regulatory guidelines for e-cigarettes. ${ }^{9}$

\section{Understanding the two vaping crises in the United States}

\section{The youth vaping epidemic}

\footnotetext{
${ }^{5}$ For a more detailed introduction to the topic, see L. Gruszczynski, Introduction: Regulating e-cigarettes in the face of uncertainty, in L. Gruszczynski (ed.), The Regulation of E-cigarettes. International, European and National Challenges, Edward Elgar Publishing: 2019, at 1-22. A good historical analysis is available in M. Zatoński \& A.M. Brandt, Divide and conquer? E-cigarettes as a disruptive technology in the history of tobacco control (idem, at 24-49).

${ }^{6}$ E.g. A. McNeill et al, Evidence Review of E-Cigarettes and Heated Tobacco Products 2018 (A report commissioned by Public Health England), Public Health England: 2018.

7 E.g. British Medical Association, E-cigarettes: Balancing risks and opportunities, 7 December 2018, $<$ https://bit.ly/2ZwDlzA> accessed 10 January 2020.

${ }^{8}$ E.g. J.F. Etter, Gateway effects and electronic cigarettes, 13 Addiction 1776 (2017); K.A. Cullen et al., ECigarette Use Among Youth in the United States, 2019, JAMA 5 November 2019, doi: 10.1001/jama.2019.18387.

${ }^{9}$ L. Gruszczynski, Taming Schrödinger's cat: E-cigarettes under the Framework Convention on Tobacco Control, in Gruszczynski (ed.), supra note 5.
} 
The youth vaping epidemic precedes EVALI, and has deeper roots. The US Food \& Drug Administration (FDA) has a long and difficult history of attempting to assert its competence to regulate tobacco products. This history culminated in 2009, when the US Congress passed the Family Smoking Prevention and Tobacco Control Act (FSPTCA), which entrusted the FDA with such powers. ${ }^{10}$ While the FSPTCA in principle applies to traditional tobacco products, it also permits expansion of its scope by authorizing the FDA to add in the future other tobaccoderived nicotine products (para. 901(b)), and hence, may apply to e-cigarettes. This mechanism is conventionally referred to as the 'deeming rule'.

Although in 2009 e-cigarettes were still a niche product, they gradually gained popularity and it soon became clear that they ought to be addressed as well. Unfortunately, the lack of a FDA's clear mandate, together with obstruction from other parts of the government and aggressive litigations by the industry, caused further regulatory delays. While actions by the FDA were being delayed, the Obama administration tried - upon a proposal from the FDA to enact a total ban on e-cigarette flavours. ${ }^{11}$ This initiative failed too, partially because of lobbying pressure and partially due to political calculations.

E-cigarettes were eventually 'deemed' in 2016. This not only extended the FDA's authority over them but also activated all relevant FSPTCA provisions for this category of products. For example, the sale to minors (under the age of 18) of e-cigarettes has been prohibited, free sampling distribution has been banned, while health warnings on the packaging have become obligatory. In addition, manufacturers, importers, and retailers of e-cigarettes have been required to comply with various reporting requirements. For some time, however, the enforcement of these provisions was too weak. This changed only in 2018 and 2019 (almost 10 years after its initial attempts to deal with e-cigarettes), when the FDA took a more proactive approach in enforcing its regulations on e-cigarettes. ${ }^{12}$

All these efforts, however, have proved to be insufficient, or at least undertaken when it was already too late. Over last three years vaping has continued to be increasingly popular among US teenagers. For example, in 2018 vaping among American teens increased by 1.5 million and passed the threshold of 5 million, with nearly 1 million using e-cigarettes on a daily basis. ${ }^{13}$ The prevalence of e-cigarette usage among this age category was also strong in 2019. It is therefore not surprising that the Surgeon-General, when drawing attention to these trends in December 2018, labelled the rise of vaping among teenagers as the 'youth vaping epidemic'. ${ }^{14}$

Hence even before the outbreak of EVALI, the US was already witnessing a different, but nonetheless troubling, vaping crisis. Against this backdrop, many public health specialists are

\footnotetext{
${ }^{10}$ P.I. Kovacevic, Regulation of E-Cigarettes in US Law, in Gruszczynski (ed.), supra note 5.

${ }^{11}$ K. Thomas \& S. Kaplan, E-Cigarettes Went Unchecked in 10 Years of F.D.A. Inaction, The New York Times, 14 October 2019, <https://www.nytimes.com/2019/10/14/health/vaping-e-cigarettes-fda.html> accessed 10 January 2020.

${ }^{12}$ E.g. K. Zernike, F.D.A. Cracks Down on 'Juuling' Among Teenagers, The New York Times, 24 April 2018, <https://nyti.ms/2svxUVG> accessed 10 January 2020.

13 FDA, Youth Tobacco Use: Results from the National Youth Tobacco Survey, 6 November 2019, <https://bit.ly/2ZxWMIB > accessed 10 January 2020.

${ }^{14}$ Assistant Secretary for Health, supra note 4.
} 
now arguing that much more could have been done, or at least done earlier, to prevent the current vaping epidemic among adolescents. ${ }^{15}$

\section{The vaping-related illness}

The outbreak of EVALI in the US can be traced back to April 2019. However, the illness was first recognized by the US Centers for Disease Control and Prevention (CDC) only in August 2019. ${ }^{16}$ The initial symptoms of EVALI are non-specific and include shortness of breath, cough, nausea, or chest pain. They progressively intensify as the illness develops and can manifest themselves in severe breathing difficulties. In the most serious cases, EVALI may lead to the complete dysfunction of the lungs and death in a few days or weeks following the onset of the symptoms. This relatively short timeframe makes EVALI markedly different from the long-term health consequences associated with tobacco smoking or exposure to tobacco smoke. EVALI has mainly affected young people rather than long-term users.

An investigation has preliminary linked EVALI to vitamin E acetate (a synthetic form of vitamin E), a chemical substance that has been found in the suspected vaping cartridges as well as in most of the fluid samples taken from the afflicted patients. ${ }^{17}$ Vitamin $\mathrm{E}$ is a common additive in food and cosmetic products, and is considered to be safe when ingested or applied topically to the skin. However, its properties are apparently different when inhaled. Unlike the other vaping components, vitamin E acetate is oily. The current hypothesis is that, being oily, vitamin $\mathrm{E}$ acetate sticks to the lungs, obstructing their normal functioning (through the accumulation of fat particles) and thus causing the injuries that have been observed in EVALI cases. $^{18}$

Vitamin E acetate is not an essential component of e-cigarettes. Actually, it has been found in those vaping products that contain tetrahydrocannabinol (THC), which is a main active substance present in marijuana. It remains, however, unclear whether vitamin $\mathrm{E}$ acetate has been intentionally added to 'thicken' the liquid or rather to dilute the THC. ${ }^{19}$ Neither is it clear how common is contaminated liquid (and/or whether contamination is limited to THC-based products or also includes some nicotine liquids), since most cartridges have been reportedly obtained by their users from the black market. ${ }^{20}$

Should the regulatory failings of the US described above also be blamed for the current EVALI crisis? Contrasting the US crisis with the situation in the EU, some commentators seem to suggest that the EU regulatory framework for e-cigarettes is better suited to prevent the

${ }^{15} \mathrm{Cf}$. Thomas and Kaplan, supra note 11; J. Howard, FDA commissioner on vaping crisis: We 'should have acted sooner', CNN, 26 September 2019, <https://cnn.it/2sycxTz> accessed 10 January 2020.

${ }^{16}$ Centers for Disease Control and Prevention, supra note 3.

${ }^{17}$ Ibid.

18 US Officials Identify "Strong Culprit" in Vaping Illnesses, AP NEWS, 8 November 2019, <https://apnews.com/80fe373103cf4096b4567cf5717380cf> accessed 10 January 2020.

${ }^{19}$ M. Thielking, Health Officials Claim Breakthrough on Vaping Illness Culprit, Scientific American, 8 November 2019, <https://www.scientificamerican.com/article/health-officials-claim-breakthrough-on-vapingillness-culprit/> accessed 10 January 2020.

${ }^{20}$ D. Grady, Vaping Illnesses Are Linked to Vitamin E Acetate, C.D.C. Says, The New York Times, 8 November 2019, <https://www.nytimes.com/2019/11/08/health/vaping-illness-cdc.html> accessed 10 January 2020. 
outbreak of an EVALI-type epidemic. ${ }^{21}$ According to this narrative, the EU regulatory framework puts in place more stringent and more effective regulations. But is this really the case? Before answering this question, let us briefly look at the relevant EU rules.

\section{Is the EU regulatory framework on e-cigarettes effectively preventing vaping crises?}

\section{The complexity of the EU regulatory framework on e-cigarettes}

The EU acted earlier than the US on e-cigarettes. The new Tobacco Products Directive (TPD), adopted in 2014, contains specific provisions for e-cigarettes, along with traditional tobacco control regulations. ${ }^{22}$ It thus created a 'sui generis regime' for these products. ${ }^{23}$ Specifically, the TPD has extended to e-cigarettes some regulatory standards applied to ordinary cigarettes, such as mandatory health warnings (although their size and their content is different) or strict advertising restrictions. At the same time, the TPD has set forth some special rules whose aim is to limit the specific (actual or potential) risks associated with e-cigarette consumption, including a ban on harmful ingredients and certain additives, and regulations on the maximum concentrations of nicotine or size of pods/tanks/e-liquid containers.

It is important to stress that the ensemble of regulations applied to e-cigarettes in EU Member States is far more complex than the TDP, and to some extent differs from country to country. While as a whole the TPD establishes the common EU regulatory framework for ecigarettes, it also leaves certain aspects unregulated and these gaps can be filled in by individual EU Member States. By way of example, there are no EU common rules on the taxation of ecigarettes, and hence each Member can tax them using different methods of calculation and different rates. ${ }^{24}$ Rules on flavours, domestic advertising and sponsorship activities, use of ecigarettes in public places, and age limitations for the purchase of e-cigarettes and e-liquids also remain within the sovereign domain of individual Member States.

In all cases, however, the regulations of EU Member States are stricter than the US requirements. This is even true for the United Kingdom (UK), which has taken a relatively liberal approach towards e-cigarettes, but still remains within the rather strict boundaries set by the EU framework. Public Health England published a report in 2015 in which it declared that e-cigarettes are 'at least $95 \%$ less harmful' than ordinary cigarettes. ${ }^{25}$ Since then, UK public health authorities have taken a fairly favourable approach to e-cigarettes. Those who have

21 S. Wheaton, Europe's Missing "Vaping Sickness", POLITICO, 12 September 2019, $<$ https://www.politico.eu/article/us-vaping-illness-death-toll-rises-fear-reversals-anti-smoking-campaigns/> accessed 10 January 2020.

${ }^{22}$ Article 20 of Directive 2014/40/EU of the European Parliament and of the Council on the Approximation of the Laws, Regulations and Administrative Provisions of the Member States Concerning the Manufacture, Presentation and Sale of Tobacco and Related Products and Repealing Directive 2001/37/EC (3 April 2014), O.J. L 127/1, 29 April 2014.

${ }^{23}$ For detailed analysis, see A. Pudło \& L. Gruszczynski, Regulating E-Cigarettes at the EU Level, in Gruszczynski (ed.), supra note 5. See also L. Gruszczynski, The EU regime for e-cigarettes: A rational compromise or regulatory failure?, 4(2) Journal of Health Inequalities 62 (2018).

${ }^{24}$ Report from the Commission to the Council on Directive 2011/64/EU on the structure and rates of excise duty applied to manufactured tobacco, $\operatorname{COM}(2018) 17$ final, 12 January 2018.

${ }^{25}$ E-Cigarettes: An Evidence Update, GOV.UK, <https://www.gov.uk/government/publications/e-cigarettesan-evidence-update> accessed 10 January 2020. 
never smoked are actively discouraged from starting vaping; but those who are smokers may be recommended to try e-cigarettes as part of a cessation therapy.

Accordingly, there is no single EU regulatory framework for e-cigarettes, but a plurality of regulatory frameworks enacted by Member States that follow the certain common rules provided by the TPD. At this point, the question becomes: are these minimal common rules (combined with the specific national requirements) enough to prevent the vaping crises we are witnessing in the US?

\section{Not preventing, but mitigating: the potential effect of the EU's sui generis regime on the EVALI and youth vaping crises}

We submit that while the framework established by the TPD could not prevent the EVALItype crisis in the EU, it has helped to keep vaping use under control, particularly among adolescents. This also entails the assumption that even if an EVALI crisis were to happen in Europe, its extent might be mitigated. There are at least two arguments to support those claims.

First, the TPD rules could make the outbreak of the EVALI epidemic slightly less likely, although they cannot fully prevent it. As noted above, most probably EVALI was caused by the use of THC-based vaping products. Such products are not covered by the TPD as they do not contain nicotine. ${ }^{26}$ Conversely, the TPD rules do apply to any nicotine-based liquids that contain vitamin E acetate. In this context, Art. 20(e) is highly relevant as it requires that all ecigarette ingredients must 'not pose a risk to human health in heated or unheated form'. However, lacking a system of pre-authorisation for the marketing of e-cigarettes (as is the case, for example, for drugs and food additives), it is not clear to what extent the European authorities can ensure the respect of this provision.

Despite lacking a system of pre-authorisation, the TPD has established a market surveillance system, which requires manufacturers/importers to notify the competent authorities of the vaping products they intend to place on the market six months before their planned placing, and to submit information on the components and ingredients of such products. While this system is imperfect, in case of an outbreak it could help the authorities to identify the responsible products and recall them (of course in a situation when the nicotine-based vapour products would be partially responsible for the outbreak of the disease). However, it is important to note that none of the TPD rules address the problem of controlling the black market in e-cigarettes, leaving such a competence with the EU Member States. ${ }^{27}$ Hence If vaping products are bought on the black market (as seems to have been the case in the EVALI epidemic in the US), the TPD would be of limited assistance in preventing the outbreak of the epidemic.

Second, and probably more important, the TPD seems to be more effective in preventing a youth vaping crisis, thus indirectly mitigating the extent of a possible EVALI epidemic. The TPD rules have prevented aggressive marketing and the targeting of youth. The existing statistics confirm that the consumption of e-cigarettes in the EU follows common patterns and are not as alarming as those that we have seen for the US. In the EU, adults over fifty are more

\footnotetext{
${ }^{26}$ This interpretation derives from a joint reading of Article 20 (on e-cigarettes) and Article 2(1)(16) (defining an e-cigarette as 'a product that can be used for consumption of nicotine-containing vapour') of the TPD.

27 Art. 15 of the TPD establishes a 'tracking and tracing' system, but limits it to tobacco products, thus excluding e-cigarettes.
} 
likely to use e-cigarettes than teenagers, and although the overall consumption of e-cigarettes is rising (including for the category of adolescents), the surge is not as stark as in the US. ${ }^{28}$

Restrictions on advertising have particularly affected the marketing potential of JUUL in the EU. JUUL is a pod-based e-cigarette which entered the US market in 2015, featuring a fashionable design, multiple sweet and attractive flavours, as well as sophisticated social media marketing campaigns. It employs an advanced technology and uses high nicotine concentration liquids. These characteristics have made JUUL a highly popular product, especially among teenagers. ${ }^{29}$ Many experts, in fact, believe that JUUL is the main factor behind the current youth vaping crisis. ${ }^{30}$ When JUUL arrived in the EU in 2018, it found a much tighter regulatory framework for advertising. Moreover, the TPD has effectively prevented the sale of products with a concentration of nicotine as high as in the JUUL e-cigarettes in the US. ${ }^{31}$ This has obviously reduced the addictiveness of the products available on the European market. Consequently, the impact of the this 'super-product' has been limited in the EU - its share remains relatively low, and it is not particularly popular among teenagers.

In this context, it should be noted that the overall popularity of e-cigarettes among US teenagers and young adults (the second group being most affected by EVALI) could have contributed to the size of the EVALI epidemic. Had e-cigarettes not been so popular, the vaping-related injuries would have probably been more limited in number. In the EVALI epidemic, as is true for many other epidemics, there are many risk factors that policymakers cannot really control, or that they can control only at a very high cost. However, the popularity of e-cigarettes is something that can, at least to some extent, be controlled by an effective regulatory framework. The EU experience seems to suggest that, as it has been done for decades with tobacco products, policymakers can affect the demand for vaping products through taxes, advertising restrictions, product standards, and other measures.

Of course, there are other reasons that may help to explain why neither the EVALI crisis nor the youth vaping epidemic has happened (yet) in the EU - at least on the scale that may be observed in the US. Those reasons are unrelated to the applicable legal regime for e-cigarettes. For example, the US, unlike the EU, seems to be in the middle of the cannabis revolution. Marijuana, the possession of which put people in prison not long ago, is now widely available in many US states, although it is still prohibited in others. Its popularity, combined with the lack of common federal rules, creates a fertile ground for the development of a black market in those states that still prohibit its sale. The black market obviously cannot be screened as to the quality of available products. At the same time, the e-cigarette revolution has not gone unnoticed among cannabis users. THC vaping products are increasingly popular, a fact that has been largely ignored so far by the US government. Accordingly, there are not yet any federal product safety standards for these products.

\footnotetext{
${ }^{28}$ A.A Laverty, F.T, Filippidis \& C.I Vardavas, Patterns, Trends and Determinants of e-Cigarette Use in 28 European Union Member States 2014-2017, 116 Preventive Medicine 13 (2018).

29 Campaign for Tobacco-Free Kids, JUUL and Youth: Rising E-Cigarette Popularity, 2019, <https://www.tobaccofreekids.org/assets/factsheets/0394.pdf> accessed 10 January 2020.

${ }^{30}$ J. Creswell, S. Kaplan, How Juul Hooked a Generation on Nicotine, The New York Times, 23 November 2019, <https://www.nytimes.com/2019/11/23/health/juul-vaping-crisis.html> accessed 10 January 2020.

${ }^{31}$ Art. 20(3)(b) of the TPD provides that the 'nicotine-containing liquid' cannot 'contain nicotine in excess of $20 \mathrm{mg} / \mathrm{ml}^{\prime}$.
} 


\section{The future of e-cigarettes after the US vaping crises}

The EVALI crisis might be a turning point in the relatively short history of e-cigarettes. Despite the fact that the illness is most probably connected with THC-based vaping products, its outbreak has been seen by various US authorities as both a warning sign and an opportunity to address the youth vaping epidemic (which, as we have seen above, could not be properly dealt with due to the various constraints). The EVALI outbreak has strengthened the position of those who favour stricter regulations for e-cigarettes; built a broader support among the general public; allowed for the allocation of resources; and attracted media attention, which generated additional pressure on the government and politicians.

The above assessment seems to be confirmed by the various regulatory initiatives undertaken by the public authorities. When the EVALI crisis unfolded, the CDC recommended the avoidance of all vaping products, which can be understood as a precautionary measure taken in a situation of scientific uncertainty. ${ }^{32}$ At the same time, however, the public authorities have taken steps more specifically aimed at the youth vaping epidemic. For example, the Trump administration announced that it would introduce, via the FDA, a federal ban on flavoured c-cigarettes. ${ }^{33}$ President Trump explained the decision by saying '[w]e can't allow people to get sick and we can't have our youth be so affected' and later added '[p]eople are dying from vaping, so we're looking at it very closely. ${ }^{34}$ These two statements were made despite the fact that there was no evidence that would connect flavoured e-cigarettes with EVALI. However, there is a broad consensus among experts that flavoured liquids are particularly attractive for teens. Unfortunately, the Trump administration later retreated from this initiative, ${ }^{35}$ and ultimately produced a watered-down requirement that only bans flavoured cartridge-based e-cigarettes (other than tobacco or menthol), such as those which are offered by JUUL. ${ }^{36}$

The US Congress was more successful when it raised the smoking age, including for ecigarettes, from 18 to $21 .{ }^{37}$ Various states/municipalities have also decided, without waiting for the federal response, to introduce their own local restrictions. Some of them have prohibited the sale of flavoured e-cigarettes (e.g. New York, Michigan and Rhode Island ${ }^{38}$ ); others imposed temporary or permanent bans on all vaping products (e.g. Massachusetts and San

\footnotetext{
${ }^{32}$ Centers for Disease Control and Prevention, supra note 2.

${ }^{33}$ S. Kaplan, Trump Administration Plans to Ban Flavored E-Cigarettes, The New York Times, 11 September

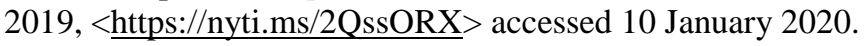

${ }^{34}$ Wheaton, supra note 21.

35 A. Karni et al., Trump Retreats from Flavor Ban for E-Cigarettes, The New York Times, 17 November 2019, <https://nyti.ms/2Swr78S >. The administration probably feared that such a decision could have an impact on the outcome of the forthcoming presidential election as the flavor ban seems to be a single issue in 17 key battleground states (see McLaughlin \& Associates, Adult Vapor Consumer Survey Battleground States, 22 October 2019, <https://bit.ly/39wLjh0> both accessed 10 January 2020).

${ }^{36}$ FDA, FDA finalizes enforcement policy on unauthorized flavored cartridge-based e-cigarettes that appeal to children, including fruit and mint, 2 January 2020, <https://bit.ly/2FrMdxp > accessed 10 January 2020.

${ }^{37}$ L. McGinley, Y. Abutaleb, Congress set to prohibit sales of tobacco products to anyone under 21, The Washington Post, 17 December 2019, <https://wapo.st/352sX41> accessed 10 January 2020.

${ }^{38}$ S. Rense, 7 States Have Moved to Ban Vapes. Is the Rest of America Next?, Esquire, 14 October 2019, <https://bit.ly/2tgbZBH> accessed 10 January 2020.
} 
Francisco ${ }^{39}$ ); or have sued e-cigarette companies (e.g. North Carolina - for understating the nicotine levels of their products and misleading the public about their potential for addiction). ${ }^{40}$ Certain private entities have also taken some steps. For example, CNN, CBS and Viacom decided to end the broadcasting of advertisements of vaping products, ${ }^{41}$ while Walmart, the largest retailer in the US, withdrew all e-cigarettes from its US offer. ${ }^{42}$ While the outbreak of EVALI has been frequently referred to, all these measures seem to be primarily concerned with the youth vaping epidemic.

The EVALI crisis, as well as its subsequent developments in the US, have also had an impact on the global regulatory landscape. Over the last couple of months several countries have either adopted comprehensive e-cigarettes bans, or introduced other types of restrictions, while others are considering the introduction of such measures in the near future. For example, the Indian government decided in September 2019 to temporarily prohibit the importation, production and sale of e-cigarettes, a measure which was subsequently followed by a permanent ban passed by the parliament in December 2019 (i.e. the Prohibition of Electronic Cigarettes Bill). ${ }^{43}$ Indonesia, Malaysia and Philippines may follow suit very soon. ${ }^{44}$ China, which is currently the largest producer of e-cigarettes, took less restrictive measures and only banned online sales of e-cigarettes, ${ }^{45}$ while South Korea is currently considering tightening its vaping product regulations. If the US does eventually opt for a stricter regulatory regime, one may expect that similar steps will be taken in other parts of the world, as the FDA is conventionally regarded as a global norm setter.

\section{Conclusions}

The report has clarified that the US is currently witnessing not one, but two distinct vaping crises: a youth vaping epidemic; and EVALI. Section II of this report briefly described the main characteristics of the US vaping crises and explained the specific political difficulties that the US authorities have faced when trying to regulate e-cigarettes.

Against this background, Section III provided some elements of a comparative analysis between the EU and the US regimes for the regulation of e-cigarettes. It demonstrated that the EU, with the adoption of the TPD, has developed some common rules for regulating e-

39 K. Lannan, Baker Declares 4-Month Ban on Vaping Product Sales, WGBH, 24 September 2019 <https://bit.ly/2sthGME> accessed 10 January 2020.

40 M. Kennedy, North Carolina Says It Is Suing 8 E-Cigarette Companies, NPR, 27 August 2019, <https://n.pr/2MAIQrJ>, accessed 10 January 2020.

${ }^{41}$ D. Yaffe-Bellany, TV Networks Take Down Juul and Other E-Cigarette Ads, The New York Times, 18 September 2019, <https://www.nytimes.com/2019/09/18/business/juul-vaping-ads-cbs.html> accessed 10 January 2020.

42 Walmart ceases e-cigarette sales, BBC, 20 September 2019, <https://www.bbc.com/news/business$\underline{49776854}>$ accessed 10 January 2020.

43 Indian parliament passes new law banning e-cigarettes, Xinhua, 3 December 2019, <https://bit.ly/354DA65> accessed 10 January 2020.

${ }^{44}$ E.g. A. Aditya, Indonesia May Join Growing Vaping Ban as Illness Hits Asia, Bloomberg, 22 November 2019, <https://bloom.bg/37qr2I9>; Malaysia considers total vaping ban after reports of U.S. deaths, Reuters, 14 October 2019, <https://reut.rs/39soZVR> both accessed 10 January 2020.

45 R. Chang, L. Du, China Bans Online Sales of E-Cigarettes, Bloomberg, 1 November 2019, <https://bloom.bg/367oLRP> accessed 10 January 2020. 
cigarettes across Member States. These rules are far from being comprehensive, and indeed important differences persist between the applicable legal frameworks in EU Member States. However, while the rules provided by the TPD are likely not sufficient to prevent an EVALI epidemic, they have prevented the onset of a youth vaping epidemic as dramatic as the in the US. To the extent that the EVALI and the youth vaping epidemics are related (as many of the people affected by EVALI are young adults), it can be affirmed that the TPD framework could mitigate the extent of a possible EVALI epidemic in the EU.

Finally, Section IV illustrated some of the most immediate consequences of EVALI in the evolution of the regulatory framework of e-cigarettes. Not surprisingly, the outbreak of the epidemic has spurred some governments (including the US) to take action to better regulate vaping products and prevent the initiation of e-cigarette usage by youth.

The findings of this report are naturally provisional and incomplete, as the investigation on EVALI is still ongoing. At the present moment, it is not clear whether the US authorities can be blamed for failing to prevent the outbreak of EVALI. What is certain, however, is that more effective regulation of e-cigarettes would have prevented the epidemic from affecting so many young adults. 